\title{
Characterization of Irrigation Water Quality of Chunnakam Aquifer in Jaffna Peninsula
}

\author{
A. Sutharsiny, S. Pathmarajah ${ }^{1 *}$, M. Thushyanthy ${ }^{2}$ and V. Meththika ${ }^{3}$ \\ Postgraduate Institute of Agriculture \\ University of Peradeniya \\ Sri Lanka
}

\begin{abstract}
Chunnakam aquifer is the main lime stone aquifer of Jaffna Peninsula. This study focused on characterization of Chunnakam aquifer for its suitability for irrigation. Groundwater samples were collected from wells to represent different uses such as domestic, domestic with home garden, public wells and farm wells during January to April 2011. Important chemical parameters, namely electrical conductivity (EC), chloride, calcium, magnesium, carbonate, bicarbonate, sulfate, sodium and potassium were determined in water samples from 44 wells. Sodium percentage, Sodium adsorption ratio (SAR), and residual Sodium Carbonate (RSC) levels were calculated using standard equations to map the spatial variation of irrigation water quality of the aquifer using GIS. Groundwater was classified based on Chadha diagram and US salinity diagram. Two major hydro chemical facies $\mathrm{Ca}-\mathrm{Mg}-\mathrm{Cl}-\mathrm{SO}_{4}$ and $\mathrm{Na}-\mathrm{Cl}-\mathrm{SO}_{4}$ were identified using Chadha diagram. Accordingly, it indicates permanent hardness and salinity problems. Based on EC, $16 \%$ of the monitored wells showed good quality and $16 \%$ showed unsuitable water for irrigation. Based on sodium percentage, $7 \%$ has excellent and $23 \%$ has doubtful irrigation water quality. However, according to SAR and RSC values, most of the wells have water good for irrigation. US salinity hazard diagram showed, $16 \%$ as medium salinity and low alkali hazard. These groundwater sources can be used to irrigate all types of soils with little danger of increasing exchangeable sodium in soil. However, $2 \%$ of the wells are not suitable for irrigation due to very high salinity and sodium hazard.
\end{abstract}

Key words: Jaffna Peninsula, Chunnakam aquifer, groundwater quality, irrigation, salinity

\section{INTRODUCTION}

The population of the Jaffna Peninsula depends entirely on groundwater resources to meet all of their water requirements. The Jaffna Peninsula has four main types of aquifer system namely Chunnakam (Valikamam area), Thenmaradchi, Vadamaradchi and Kayts (Puvaneswaran, 1986). Limestone is the main aquifer in the Jaffna Peninsula. The low salinity groundwater lenses that constitute the Jaffna Peninsula aquifer system are the only sources of drinking water for the Peninsula. Freshwater lenses also supply a large proportion of supplementary irrigation water in the Peninsula (Punthakey \& Nimal, 2006). Therefore, groundwater is an extremely valuable resource in the Peninsula and pollution of groundwater is a matter of serious concern.

Department of Agricultural Engineering, Faculty of Agriculture, University of Peradeniya, Peradeniya, Sri Lanka

Department of Agricultural Engineering, Faculty of Agriculture, University of Jaffna, Jaffna, Sri Lanka

Institute of Fundamental Studies, Hantana Road, Kandy, Sri Lanka

Author for correspondence: s_pathma@yahoo.com 
Valikamam area is an intensified agricultural area in Jaffna Peninsula. Agriculture is the main source of livelihood for $65 \%$ of the population and about $34.2 \%$ of the land is cultivated intensively and commercially with high value cash crops such as red onion, chillies, potatoes, tobacco, vegetables, banana and grapes for commercial purposes in Peninsula (Thadchagini \& Thiruchelvam, 2005). Therefore, assessment of groundwater for irrigation has become a necessary and important task for present and future groundwater quality management. The suitability of water for irrigation is determined not only by the total amount of salt present but also by the kind of salt. Various soil and cropping problems develop as the total salt content increases, and special management practices may be required to maintain acceptable crop yields. Water quality or suitability for use is judged on the potential severity of problems that can be expected to develop during long term use. Hence, the present study was focused on characterization of Chunnakam aquifer for its suitability for irrigation. The data used in this study covers the period from January 2011 to April 2011 as it represents a critical period covering end of wet season to beginning of dry season. The purpose was to characterize the suitability for irrigation water from Chunnakam aquifer at the beginning of a dry season which is critical for irrigated agriculture in the study area.

\section{MATERIALS AND METHODS}

\section{Description of the study area}

The Jaffna Peninsula is in the northern most part of Sri Lanka. The major soils in the Peninsula are the calcic red-yellow latosols which are variable in depth, fine textured and well-drained with very rapid infiltration rate (De Alwis \& Panabokke, 1972). Figure 1 shows the location of the freshwater lens in Jaffna Peninsula. The most intensively exploited areas are the urban areas of Jaffna, Chavakachcheri and Point Pedro. For rural water use the most heavily exploited areas are in Valikamam East and a small zone in Valikamam West.

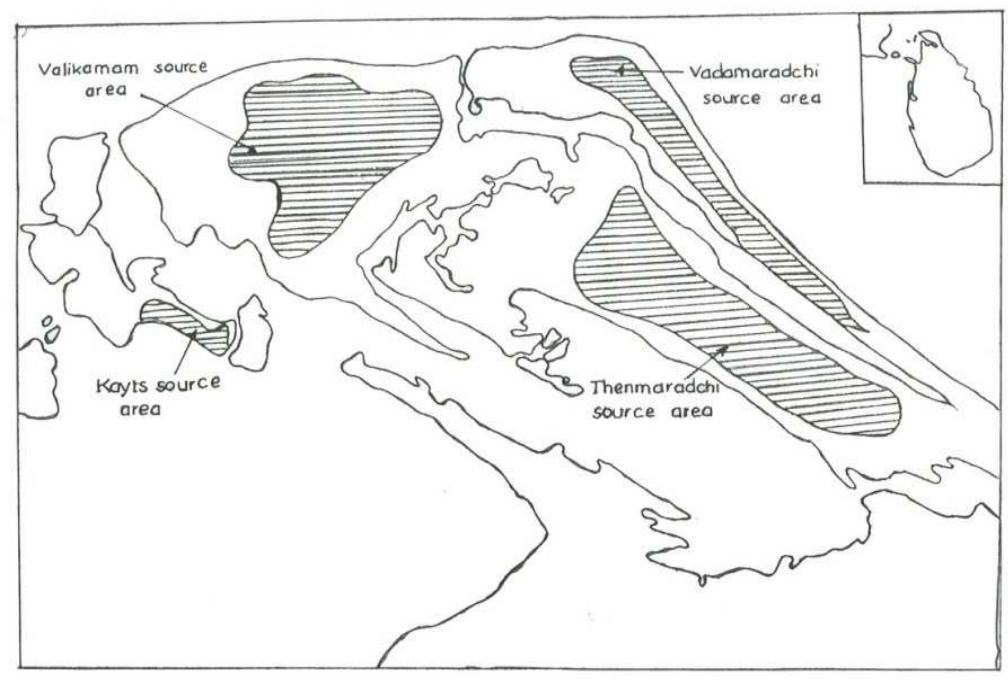

Fig. 1. Groundwater resources in Jaffna Peninsula (Source: Puvaneswaran, 1986) Selection of wells 
Forty four wells were selected for long term water quality monitoring in a systematic manner to represent the entire Chunnakam aquifer. All selected wells are under multiple usages such as domestic wells ( 2 wells), wells for domestic and home gardening (9 wells), public wells for drinking purpose ( 9 wells), and farm wells ( 24 wells). Figure 2 shows the locations of the wells selected for monitoring in Chunnakam aquifer in the Valikamam area in Jaffna Peninsula.

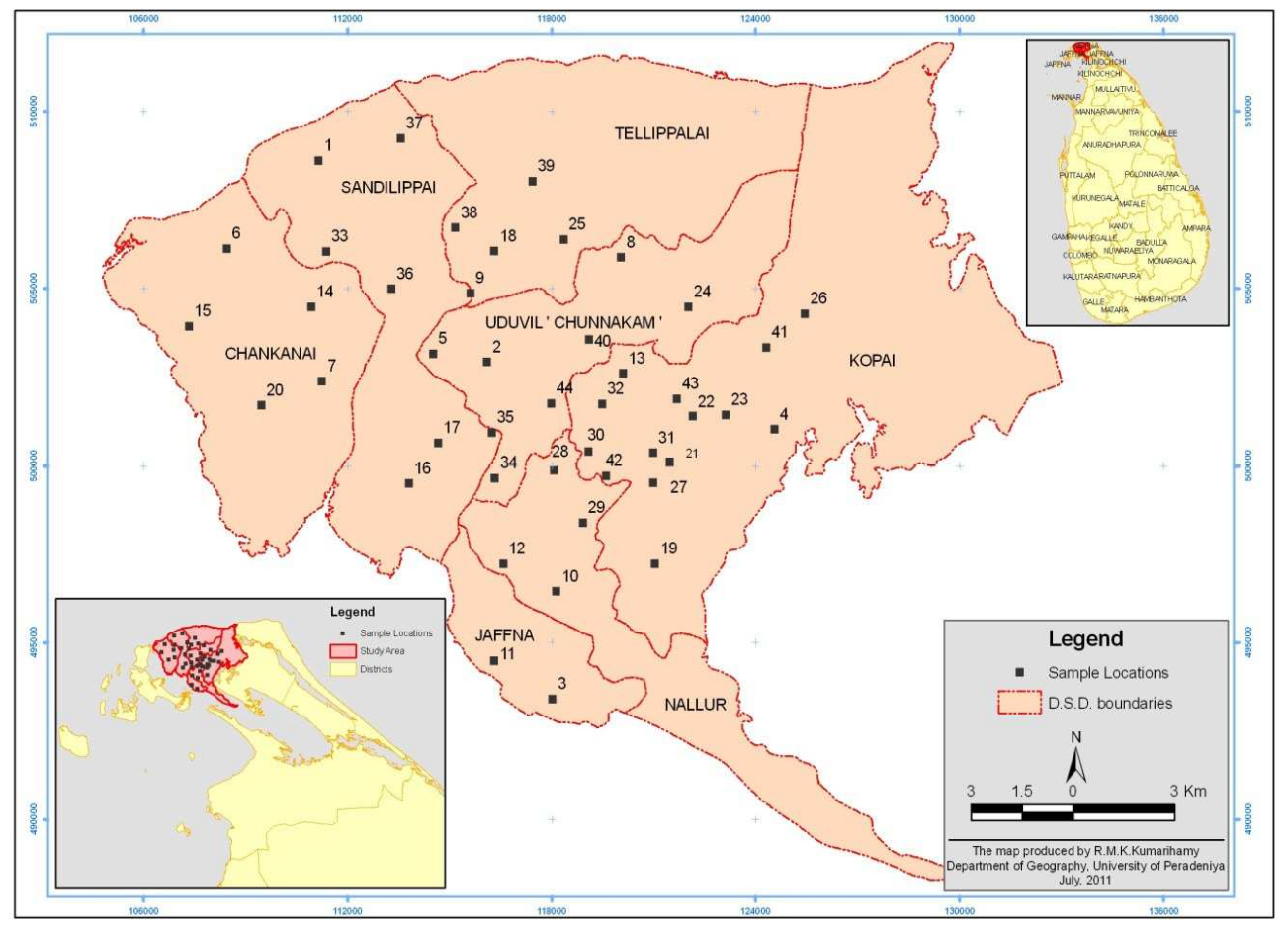

Fig. 2. Location of selected wells with DS divisions in Chunnakam aquifer area

\section{Collection of water samples}

It was intended to collect water samples for chemical analysis five times during the period from January to December, 2011 to represent various rainfall regimes within a year. However, a period between wet and dry seasons is covered in this study to characterize the aquifer for irrigation water quality. As such, sampling was carried out in mid January, early part of March and mid April, 2011. Each sample was poured into 1 litre plastic bottles after rinsing several times with the same water. These bottles were tightly closed, labeled and transported to the laboratory of the National Water Supply and Drainage Board (NWS\&DB), Jaffna for analysis within 48 hours after collection.

Samples were analyzed for Electrical Conductivity (EC), calcium, magnesium, chloride, carbonate, bicarbonate, sulfate, sodium and potassium concentrations. Conductivity meter was used to measure EC. Calcium and magnesium content were determined by EDTA titration using Eriochrome black $\mathrm{T}$ as indicator. Chloride concentration was measured by silver nitrate titration. Carbonate and bicarbonate contents were measured by acid-base titration. Sulfate contents were estimated by turbidimetric method using turbidity meter. 
Sodium and potassium content were determined by using a flame photometer in Institute of Fundamental Studies (IFS), Hantana, Kandy. The procedures of the analysis were based on Sri Lankan Standard 614 (SLS, 1983). Sodium percentage (Wilcox, 1955), Sodium Adsorption Ratio (SAR) (Richards, 1954) and Residual Sodium Carbonate (RSC) (Eaton, 1950) levels were calculated using standard equations. Groundwater was classified based on Chadha diagram (Chadha, 1999) and US salinity diagram (U.S. Salinity Laboratory Staff, 1954). Spatial distribution maps for different parameters were developed using ArcGIS 9.2. Here, IDW interpolation technique was used to create the maps.

\section{RESULTS AND DISCUSSION}

\section{Classification of the groundwater based on chemical facies}

To classify the groundwater and to identify the hydro-chemical processes, a Chadha diagram (Chadha, 1999) is used. This diagram is a somewhat modified version of the Piper diagram (Piper, 1944) and the expanded Durov diagram (Durov, 1948). In Chadha's diagram (Fig. 3), the difference in milliequivalent percentage between alkaline earths $\left(\mathrm{Ca}^{2+}+\mathrm{Mg}^{2+}\right)$ and alkali metals $\left(\mathrm{Na}^{+}+\mathrm{K}^{+}\right)$, expressed as percentage reacting values, is plotted on the $\mathrm{X}$ axis and the difference in milliequivalent percentage between weak acidic anions $\left(\mathrm{CO}_{3}{ }^{2-}+\mathrm{HCO}_{3}\right)$ and strong acidic anions $\left(\mathrm{Cl}^{-}+\mathrm{SO}_{4}{ }^{2-}\right)$ is plotted on the $\mathrm{Y}$ axis. From this diagram, $66 \%$ of the groundwater samples fall in the field of 6 . It belongs to the $\mathrm{Ca}^{2+}-\mathrm{Mg}^{2+}-\mathrm{Cl}^{-}$type hydrochemical facies. Such water has permanent hardness and does not deposit residual sodium carbonate in irrigation use. Another $32 \%$ of the groundwater samples fall in the field of 7 which belongs to $\mathrm{Na}^{+}-\mathrm{Cl}^{-}-\mathrm{SO}_{4}{ }^{2-}$ hydro-chemical facies and represents $\mathrm{Na}^{+}$-dominant $\mathrm{Cl}^{-}$type, or $\mathrm{Cl}^{-}$-dominant $\mathrm{Na}^{+}$-type waters. Such water generally creates salinity problems both in irrigation and drinking uses. Few samples ( $2 \%$ ) fall in the field of 5 which belongs to the $\mathrm{Ca}^{2+}-\mathrm{Mg}^{2+}-\mathrm{HCO}_{3}{ }^{-}$type and such water has temporary hardness.

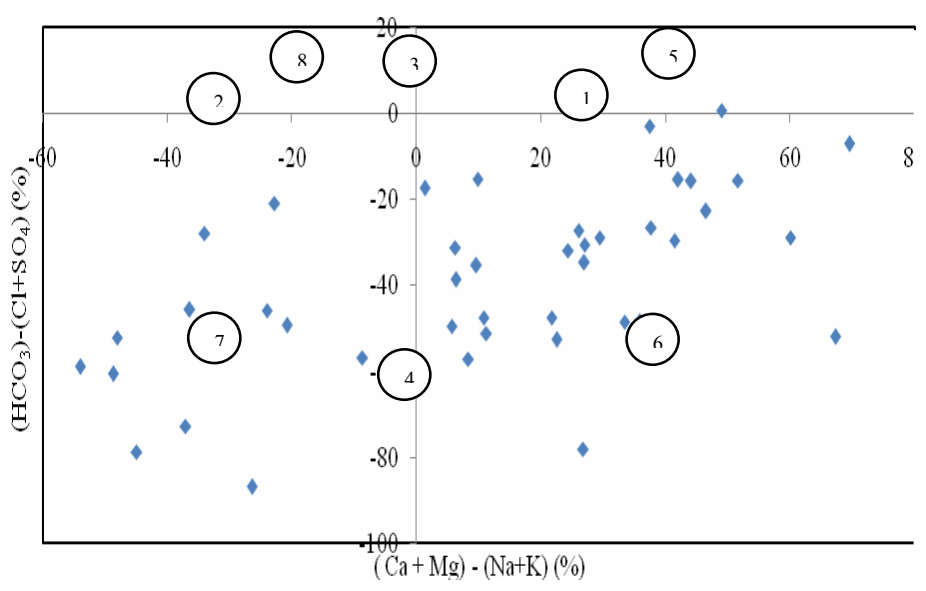

1. Alkaline earth exceeds alkali metals.

2. Alkali metals exceed alkaline earth.

3. Weak acidic anions exceed strong acidic anions.

4. Strong acidic anions exceed weak acidic anions

5. Represent $\mathrm{Ca}^{2+}-\mathrm{Mg}^{2+}-\mathrm{HCO}_{3}$ type.

6. Represents $\mathrm{Ca}^{2+}-\mathrm{Mg}^{2+}-\mathrm{Cl}^{-}$ type.

7. Represent $\mathrm{Na}^{+}-\mathrm{Cl}^{-}$- type, $\mathrm{Na}_{2} \mathrm{SO}_{4}$ - type.

8. Represent $\mathrm{Na}^{+}-\mathrm{HCO}_{3}{ }^{-}$-type.

Fig. 3. Groundwater quality plotted on Chadha diagram 


\section{Irrigation water quality in selected wells}

\section{Salinity hazard}

EC is a good measurement of salinity hazard to crop when using groundwater for irrigation. Classification of groundwater based on salinity hazard was done according to the recommendation of Wilcox (1955). It was grouped as Excellent $(100-250 \mu \mathrm{S} / \mathrm{cm})$, Good $(250-750 \mu \mathrm{S} / \mathrm{cm})$, Doubtful $(750-2,250 \mu \mathrm{S} / \mathrm{cm})$ and Unsuitable $(>2,250 \mu \mathrm{S} / \mathrm{cm})$. Based on EC, $16 \%$ of the selected wells have good quality, $68 \%$ have doubtful quality and $16 \%$ have unsuitable quality (Fig. 4). Nishanthiny et al. (2010) reported that based on EC, $44 \%$ of the wells have good quality water, $47 \%$ have doubtful quality water and $9 \%$ have unsuitable quality water in water supply wells of Jaffna Peninsula.

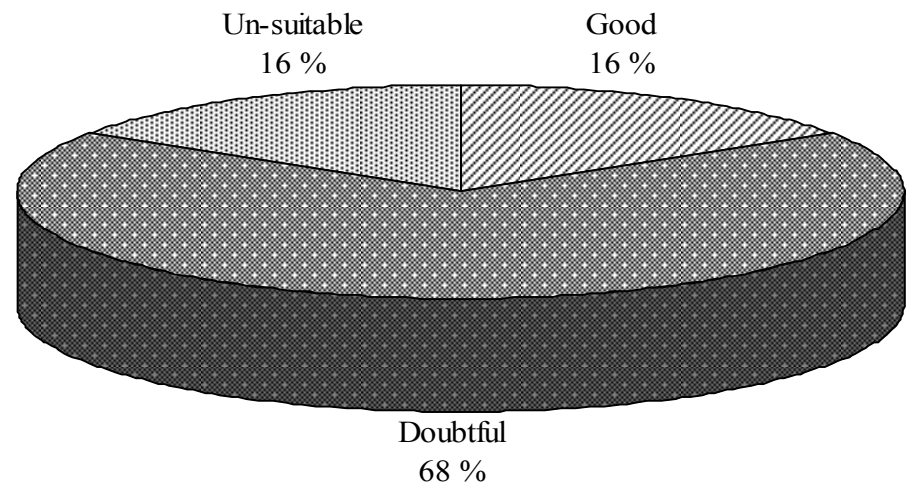

Fig. 4. Irrigation water quality based on EC

Spatial variation of salinity in Chunnakam aquifer for April 2011 is shown in Fig. 5. Based on EC, $20 \%$ of the wells are good for irrigation, $62 \%$ of the wells have high salinity water which is doubtful for irrigation and $18 \%$ of the wells come under unsuitable for irrigation.

The primary effect of high EC water on crop productivity is the inability of the plant to compete with ions in the soil solution for water. Higher the EC, less water is available to plants (Tatawat \& Chandel, 2008). Several wells once used to supply potable water are not in use now due to the increase of salinity (Nandakumar, 1983). Fresh groundwater is underlain by saline water. Pumping a well in the fresh water zone causes the fresh water-salt water interface to rise below the well. Care must be taken to prevent or minimize the chances of saline water contamination during pumping from the ground aquifer. To avoid upward movement of saline water minimum draw down should be maintained during groundwater extraction. 


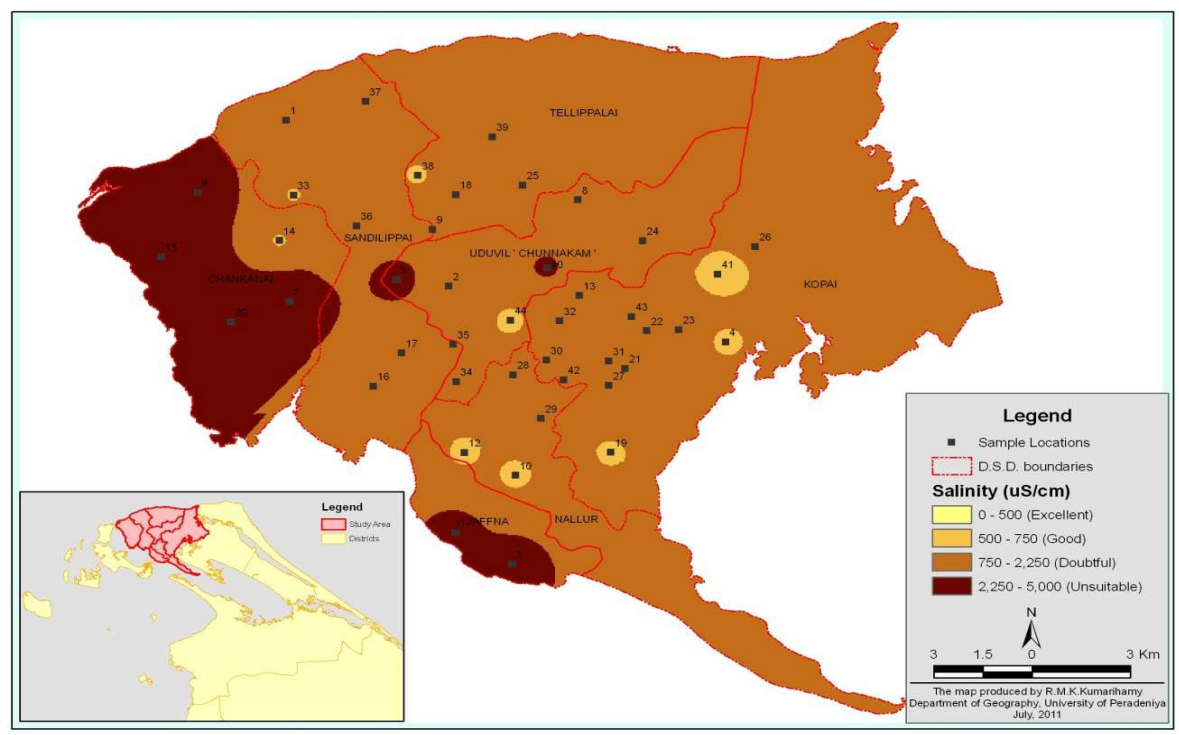

Fig. 5. Spatial variation of salinity in Chunnakam aquifer for April 2011

\section{Sodium hazard}

\section{Sodium percentage ( $\mathrm{Na} \%)$}

Sodium concentration plays an important role in evaluating irrigational quality of groundwater. A high concentration of sodium is undesirable as sodium is adsorbed on the exchange sites causing soil aggregates to disperse, reducing its permeability (Arshid et al., 2011). The sodium in irrigation waters is also expressed as percent sodium or soluble-sodium percentage $(\mathrm{Na} \%)$ and the sodium percentage was calculated by using formula proposed by Wilcox (1955).

According to Wilcox (1955), groundwater was grouped based on average percent sodium as Excellent $(<20 \%)$, Good (20-40\%), Permissible (40-60\%), Doubtful $(60-80 \%)$ and Unsuitable ( $>80 \%$ ). Out of selected wells, $7 \%$ have excellent irrigation water quality, $40 \%$ have good irrigation water quality, $30 \%$ have permissible irrigation water quality and $23 \%$ have doubtful irrigation water quality (Fig. 6).

Spatial variation of $\mathrm{Na} \%$ for April 2011 in Chunnakam aquifer is shown in Fig. 7. Accordingly, $7 \%$ of the selected wells have excellent irrigation water quality, $34 \%$ have good irrigation water quality, $34 \%$ have permissible irrigation water quality, $23 \%$ have doubtful irrigation water quality and $2 \%$ have unsuitable for irrigation. Well-4 comes under unsuitable which is used for domestic and home garden purposes. When the concentration of sodium ion is high in irrigation water, $\mathrm{Na}^{+}$tends to be absorbed by clay particles, displacing magnesium and calcium ions. This exchange process of sodium in water for $\mathrm{Ca}^{2+}$ and $\mathrm{Mg}^{2+}$ in soil reduces the permeability and eventually results in soil with poor internal drainage (Belkhiri et al., 2010). However, this situation is unlikely in Jaffna as the soils have high permeability and low clay content. 


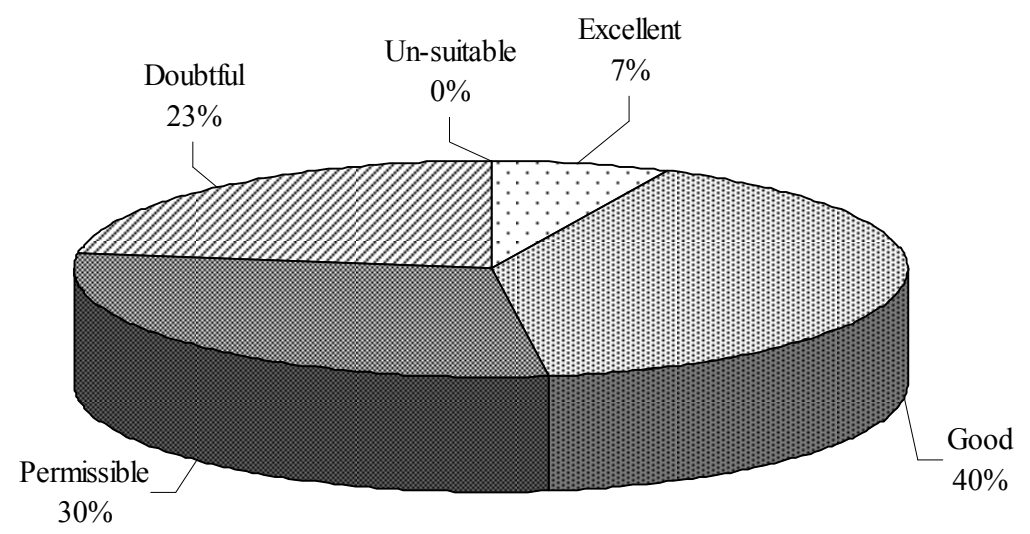

Fig. 6. Irrigation water quality based on $\mathrm{Na} \%$

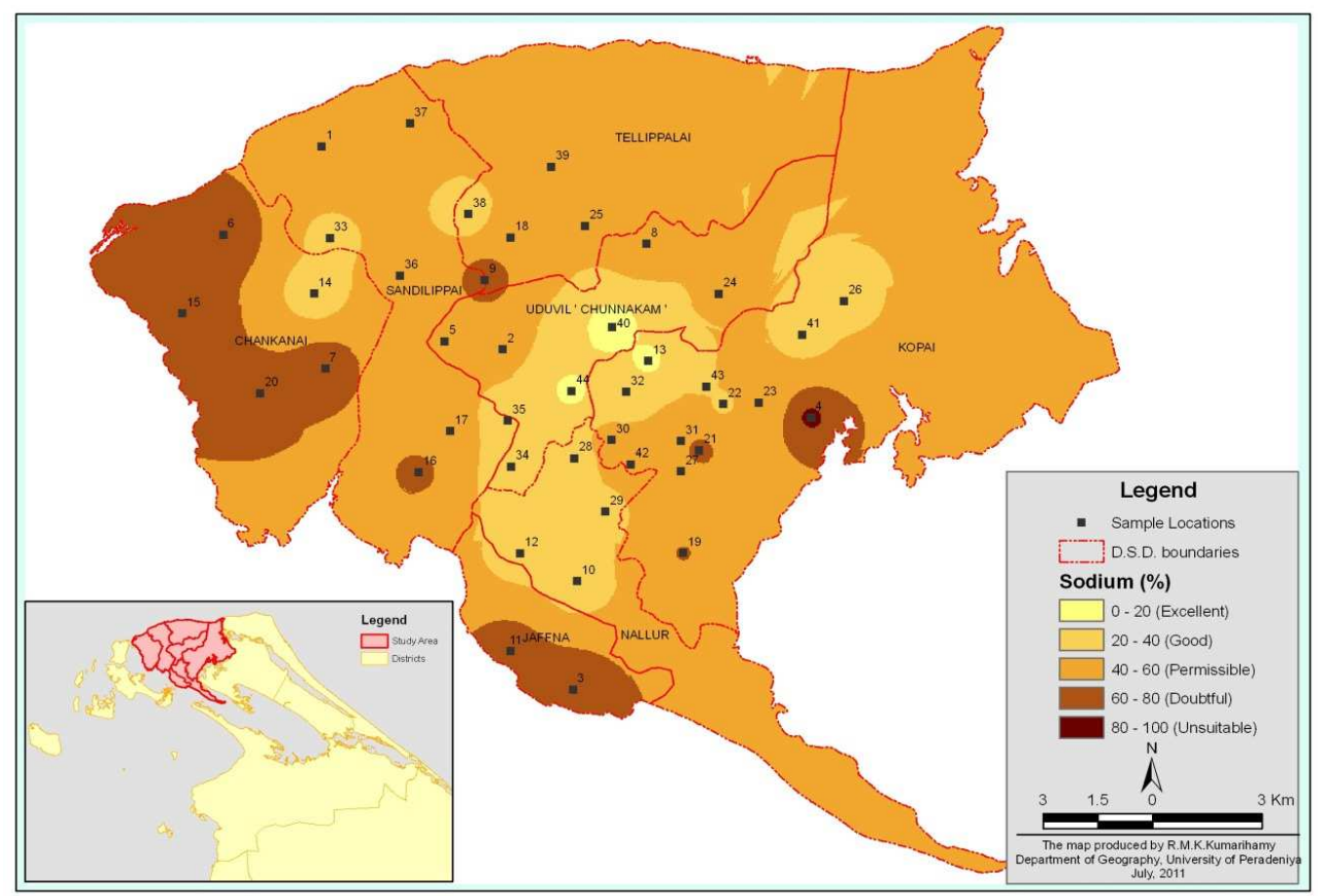

Fig. 7. Spatial variation of $\mathrm{Na} \%$ in Chunnakam aquifer for April 2011

\section{Sodium Absorption Ratio (SAR)}

Sodium hazard is also usually expressed in terms of the SAR. SAR is an important parameter for determination of suitability of irrigation water. SAR values for each water sample were calculated by the formula proposed by Richards (1954).

Groundwater could be also classified based on SAR as Excellent (10), Good (10-18), Doubtful (18-26) and Unsuitable (>26) (Richards, 1954). As per the classification based on 
average SAR values $91 \%$ of the samples fall in to excellent category while the rest (9\%) belongs to good category. This result indicates that most of the area is suitable for irrigation with no danger of exchangeable sodium. All sampling points are falling under between excellent to good category. This result was supported by Nishanthiny et al. (2010) that almost all the wells have good quality irrigation water in Jaffna Peninsula.

Classification of groundwater based on the SAR value for April 2011 in Chunnakam aquifer is shown in Figure 8. All sampling points are falling between excellent (84 \%) and good (16 $\%$ ) category. This figure also indicates that most of the areas are suitable for irrigation with no danger of exchangeable sodium.

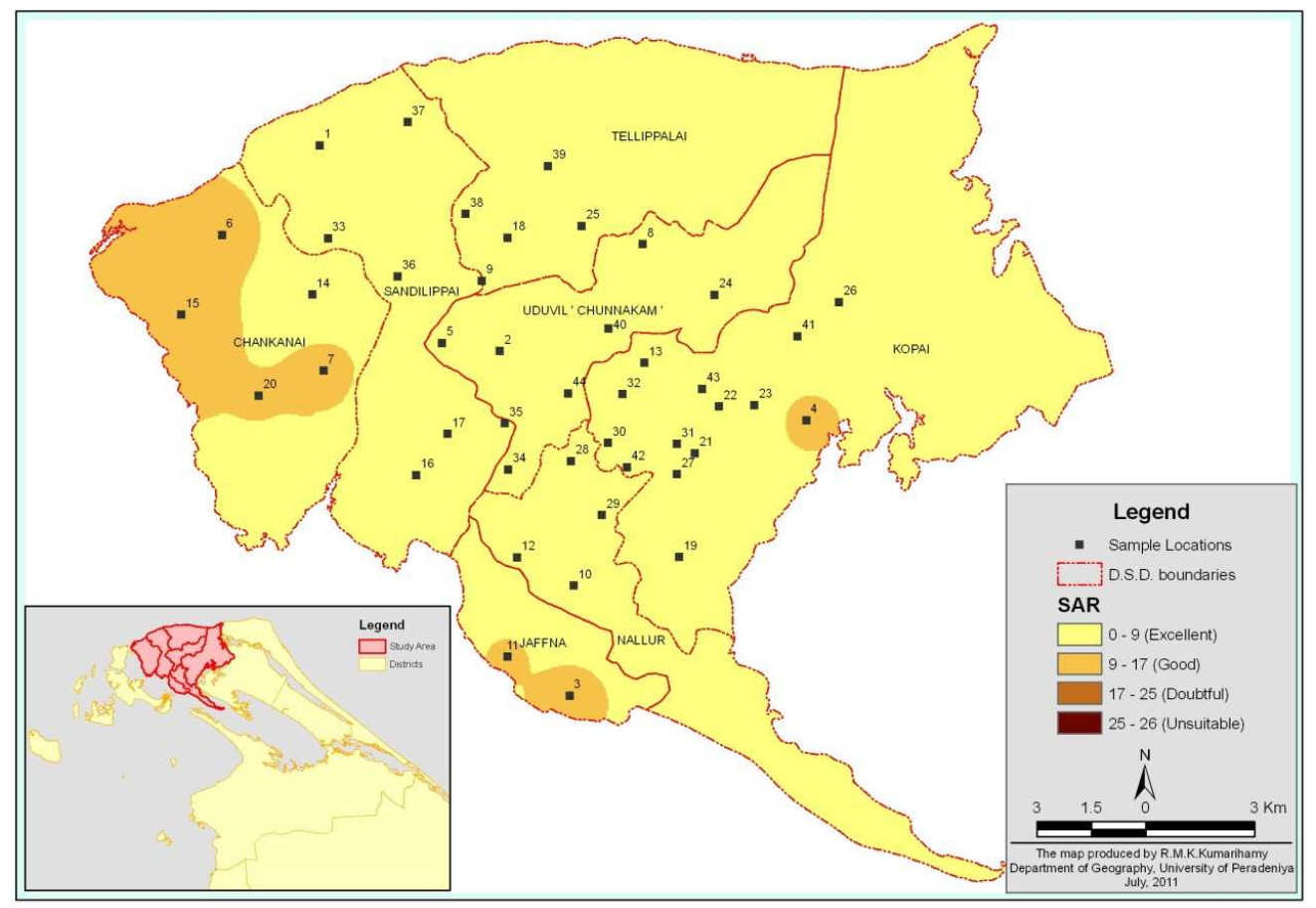

Fig. 8. Spatial variation of SAR value in Chunnakam aquifer for April 2011

\section{Bicarbonate hazard}

\section{Residual Sodium Carbonate (RSC)}

Residual sodium carbonate (RSC) is an index used to determine the bicarbonate hazard as well as to distinguish between the different water classes for irrigation purposes. In water having high concentration of bicarbonate there is tendency for calcium and magnesium to precipitate as carbonates. To qualify this effect an experimental parameter termed as RSC was used. The classification of water quality for irrigation on the basis of RSC was proposed by Eaton (1950).

Residual carbonate levels less than $1.25 \mathrm{meq} / \mathrm{l}$ are considered safe. Waters with RSC of 1.25 $-2.50 \mathrm{meq} / \mathrm{l}$ are within the marginal range. It was grouped as Good $(<1.25)$, Doubtful $(1.25-$ 
2.5) and Unsuitable (> 2.5). Based on average RSC, all the samples fall in good category except sample $2 \%$, which fall in doubtful category. Fig. 9 shows the spatial variation of RSC in Chunnakam aquifer for April 2011. As shown in the figure, $66 \%$ of the wells comes under good quality for irrigation, $23 \%$ of wells come under doubtful and $11 \%$ come under unsuitable for irrigation.

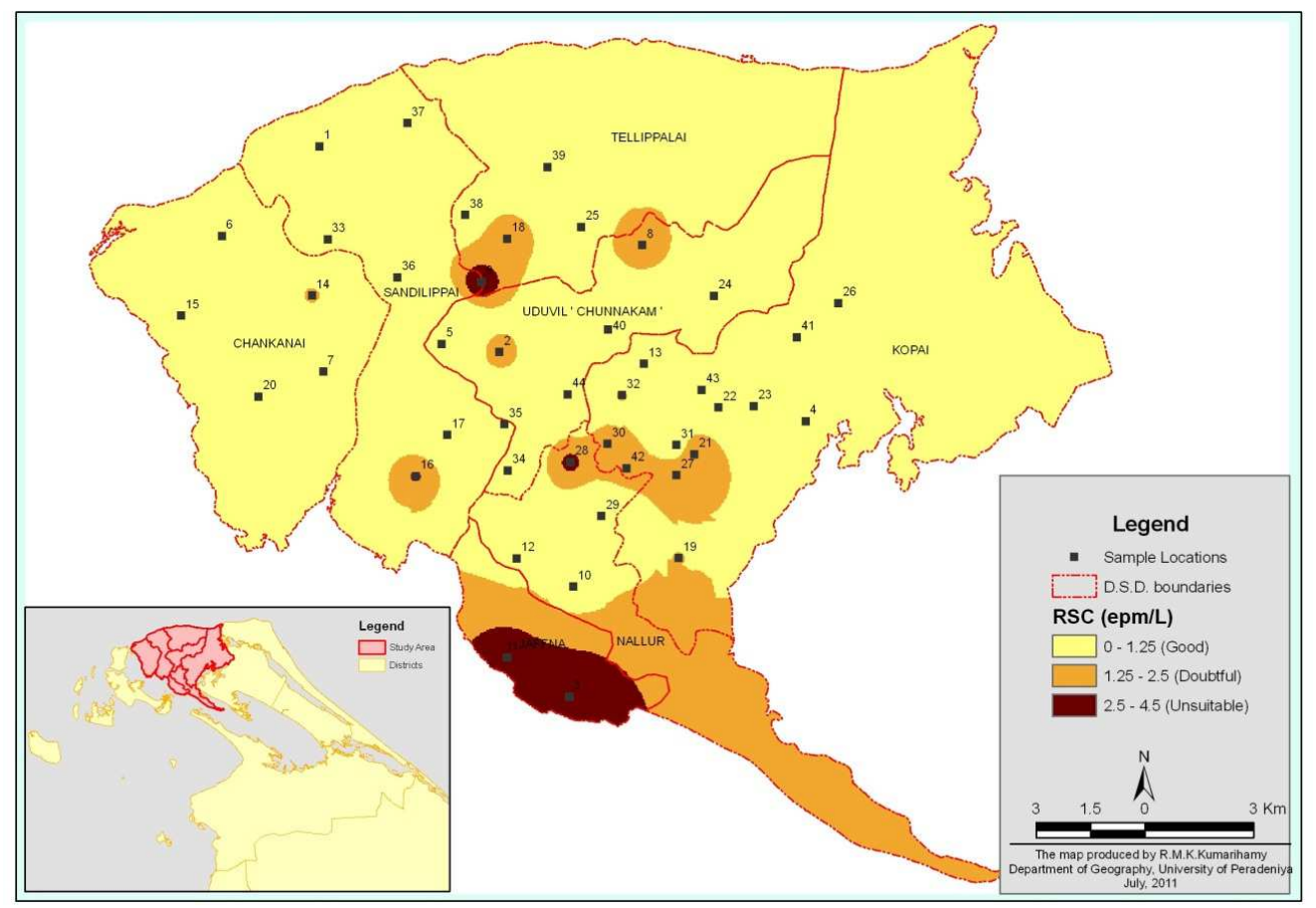

Fig. 9. Spatial variation of RSC value in Chunnakam aquifer for April 2011

Continuous use of waters having RSC more than $2.5 \mathrm{meq} / 1$ leads to salt build up which may hinder the air and water movement by clogging the soil pores and lead to degradation of the physical condition of soil. RSC values ranging from $2.5-4$ meq/l can be used effectively with the addition of gypsum.

\section{Irrigation water classification}

The combination of EC and SAR had also been used to determine the suitability of water for irrigation. The US salinity diagram (U.S. Salinity Laboratory Staff, 1954) was used to classify the groundwater samples for irrigation. In US salinity diagram, EC is taken as salinity hazard and SAR as alkalinity hazard (Fig. 10). Out of 44 ground water samples tested, $16 \%$ fall under $\mathrm{C} 2 \mathrm{~S} 1$, indicating medium salinity and low alkali hazard. These groundwater sources can be used to irrigate all types of soils with little danger of exchangeable sodium. Most of the groundwater samples (60\%) fall in C3S1 quality with high salinity hazard and low sodium hazard. Sample-15 comes under C4S4 class which is not suitable for irrigation. It is a public well and located near coastal area. Nine percent of wells fall in C3S2 quality with high salinity hazard and medium sodium hazard and another $9 \%$ fall in C4S3 quality with very high salinity hazard and high sodium hazard. Sample-5 falls in 
C4S1 showing very high salinity hazard and low sodium hazard and Sample-11 falls in C4S2 showing very high salinity hazard and medium sodium hazard. Salinity in C3S2, C4S2, $\mathrm{C} 4 \mathrm{~S} 3$ and C4S4 classes is either high or very high. It results in sodium problem in most soils and not suitable for irrigation under ordinary conditions. This water can be used on soils with considerable drainage like in the case of the study area. However, even with adequate drainage, special measures for salinity control may be required. Salt tolerant plants like asparagus, beet, sorghum, and cauliflower could be selected to grow in these soils.

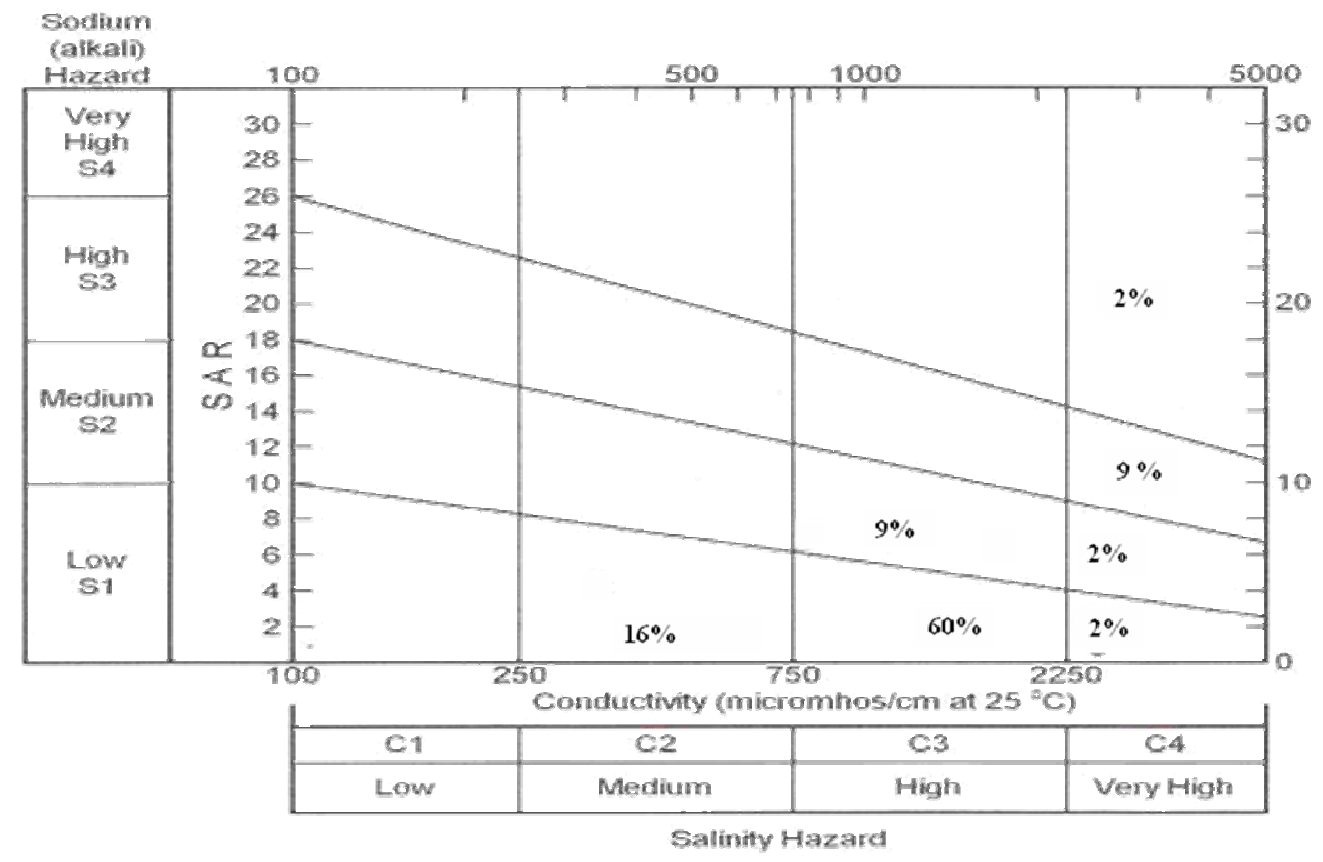

Fig. 10. Groundwater classification according to US salinity diagram (1954)

\section{CONCLUSIONS}

The aquifer belongs to two major hydro chemical facies namely Ca-Mg-Cl-SO4 and Na-Cl$\mathrm{SO}_{4}$. Accordingly, permanent hardness and salinity problems are probable. Based on EC, 68 $\%$ of the selected wells have high salinity or doubtful irrigation water and $16 \%$ have very high salinity or unsuitable irrigation water. In areas where irrigation water quality is doubtful, there is a risk of yield reduction for most of the commonly cultivated crops like tomato, cabbage, cauliflower, potato, onion, carrot, bean, tobacco and grapes. Adequate drainage and special salinity control measures may be required to cultivate sensitive crops. Based on sodium concentration, $7 \%$ of the selected wells have excellent irrigation water quality, $40 \%$ have good irrigation water quality, $30 \%$ have permissible irrigation water quality and $23 \%$ have doubtful irrigation water quality. As per the classification based on SAR values $91 \%$ of the samples fall into excellent category while $9 \%$ belong to good category. According to salinity hazard diagram, $16 \%$ of wells have medium salinity and low alkali hazard. These groundwater sources can be used to irrigate all types of soils with little danger of exchangeable sodium. Sixty percent of wells have high salinity hazard and low sodium hazard, whereas, $9 \%$ have high salinity hazard and medium sodium hazard and 
another $9 \%$ have very high salinity hazard and high sodium hazard. Two percent of the wells have very high salinity hazard and low sodium hazard and another $2 \%$ have very high salinity hazard and medium sodium hazard.

\section{ACKNOWLEDGEMENT}

Financial support provided by the Crossing Boundaries project of the PGIA, University of Peradeniya and International Water Management Institution is gratefully acknowledged.

\section{REFERENCES}

Arshid, J., Aasimah, T., Yousuf, A.R., Akbar, M. and Aabid, H.N. (2011). Geochemistry and irrigation quality of groundwater along River Jhelum in South Kashmir, India. Recent Res. in Sci. and Tech. 3(6), 57-63.

Belkhiri, L., Boudoukha, A. and Mouni, L. (2010). Groundwater quality and its suitability for drinking and agricultural use in Ain Azel plain, Algeria. Journal of Geography and Regional Planning. 3(6), 151-157. (http://www.academicjournals.org/jgrp).

Chadha, D.K. (1999). A proposed new diagram for geochemical classification of natural waters and interpretation of chemical data. Hydrogeol. J. 7,431-439.

De Alwis, K.A. and Panabokke, C.R. (1972). Handbook of Soils of Sri Lanka (Ceylon). Soil Sci. Soc., Ceylon 2, 1-97.

Durov, S.A. (1948). Natural waters and graphic representation of their compositions. Akademiya Nauk SSSR Doklady.59, 87-90.

Eaton, F.M. (1950). Significance of carbonates in irrigation waters. Soil Sci. 69, 123-133.

Nandakumar, V. (1983). Natural environment and groundwater in Jaffna Peninsula, Sri Lanka. Climatological notes, Tsukuba, Japan. 33, 155-164.

Nishanthiny, S.C., Thushyanthy, M., Barathithasan, T. and Saravanan, S. (2010). Irrigation Water Quality Based on Hydro Chemical Analysis, Jaffna, Sri Lanka. American-Eurasian J. Agric. Environ. Sci. 7 (1), 100-102.

Piper, A.M. (1944). A graphic procedure in geochemical interpretation of water analyses. Am. Geophys. Union Transactions. 25, 914-923.

Punthakey, J.F. and Nimal, P.D. (2006). Coupled flow and salinity transport modelling and assessment of groundwater availability in the Jaffna Peninsula, Sri Lanka. 32nd WEDC International Conference. 2006. Colombo, Sri Lanka. pp 326-327.

Puvaneswaran, P. (1986). Geomorphology of the Valukkai aru drainage basin. Sri Lankan. J. South Asian Sudies. 1, 43-58. 
Richard, L.A. (1954). Diagnosis and improvement of saline and alkali soils. Agric. handbook 60, USDA, Washinon DC.

SLS (1983). Sri Lanka Standard 614: part 1. Specification for potable water physical and chemical requirements. pp 5-10.

Tatawat, R.K. and Chandel, C.P.S. (2008). Quality of groundwater of Jaipur city, Rajasthan (India) and its suitability for domestic and irrigation purpose. App. Ecol. and Environ. Res. 6(2), 79-88. (Http://www.ecology.uni-corvinus.hu).

Thadchayini, T. and Thiruchelvam, S. (2005). An economic evaluation of drip irrigation project for banana cultivation in Jaffna district Pp. 111-126. In Galagedara, L.G. (Ed). Water Resources researches in Sri Lanka, Symposium proceedings of the water professionals' day2005.

U.S. Salinity Laboratory Staff. (1954). Diagnosis and Improvement of Saline and Alkali Soils. - Handbook 60, U.S. Department of Agriculture, Washington.

Wilcox, L.V. (1955). Classification and Use of Irrigation Waters. U.S. Dept. Agric. Circular 969, Washinton, U.S. Dept. Agric 